\title{
Disposições e contextos de ação: o esporte em questões ${ }^{1}$
}

Bernard Lahire*

\begin{abstract}
Resumo: Nesse ensaio, mesmo que se colocando numa condição de não ser exatamente um sociólogo do esporte, o autor pergunta como seu texto poderia ser útil para aqueles que conhecem muito melhor essa área do que ele. Em resposta a essa questão, inicia dando exemplos do que a Sociologia do Esporte não deve ser; com essa crítica, acaba apoiando aqueles que trabalham diariamente na construção de uma sociologia científica do esporte. Em seguida, com base no ponto de vista de sociólogo disposicionalista, propõe uma série de linhas de pesquisas articuladas, a partir de um conjunto de questões e algumas observações e/ou sugestões. Por fim, diz por que pensa que a Sociologia do Esporte poderia ser um lugar essencial de renovação e de progressão de uma Sociologia da educação que se reconciliaria com suas ambições científicas de Sociologia da socialização.
\end{abstract}

Palavras chave: Futebol. Sociologia do esporte. Educação

Nos anos 1950, quando o sociólogo Norbert Elias começa a trabalhar sobre questões esportivas (especialmente sobre o futebol), na Inglaterra, o interesse e a dignidade acadêmicos desses objetos estão longe de serem reconhecidos. Desde então, as coisas mudaram bastante, a ponto de o esporte ter se tornado um tema recorrente de muitos ensaístas, que insistem em tornar obscuro o que outros se esforçam para esclarecer. Não é por acaso que a Sociologia do Esporte continua sendo uma especialidade dominada dentro da disciplina.

\footnotetext{
*Professeur de sociologie à l'École Normale Supérieure de Lyon. Lyon, France. E-mail: lahire@mail.univ-lyon2.fr

${ }^{1}$ Este texto foi inicialmente publicado na França, na obra intitulada L'Esprit sociologique. Paris: Éditions la Découverte, 2004. Tradução de Patricia C.R. Reuillard e Paula Malaszwiecz (UFRGS).
} 
Essa situação se deve por um lado, é claro, ao lugar que as atividades corporais e esportivas ocupam - enquanto lazeres ou divertimentos que não pertencem às formas mais apreciadas de cultura legítima - no conjunto hierarquizado das práticas sociais. Mas ela também depende das ambições científicas que os pesquisadores investem nessas questões. Dessa maneira, embora eu não tenha certeza de que Norbert Elias (1994, p. 25) tivesse totalmente razão ao escrever que "[...] o conhecimento do esporte é a chave do conhecimento da sociedade" (seria possível, com efeito, dizer o mesmo de qualquer outro objeto), é justamente com tais motivações de pesquisa que se pode fazer com que a Sociologia do Esporte traga uma contribuição maior para a análise de nossas formações sociais.

\section{Generalistas e Especialistas}

Com que direito se pode participar das reflexões e dos debates próprios a um campo especializado de disciplina, quando não se é propriamente um "especialista" da área? Embora ocorra de eu orientar trabalhos sobre o esporte, e ainda que as atividades corporais e esportivas (mais geralmente as relações socialmente diferenciadas com o corpo) fossem uma das dimensões trabalhadas no programa de pesquisa que originou a publicação de uma obra recente (LAHIRE, 2002), , não sou o que normalmente se chama de "sociólogo do esporte". Possivelmente o convite que me foi feito para falar sobre esse tema está relacionado ao fato de que me inscrevo, ainda que de maneira crítica em uma série de pontos, em uma tradição sociológica (disposicionalista) que, sobretudo através das reflexões de Pierre Bourdieu, originou numerosos trabalhos nessa área. (CLEMENT, 1994, 1998; FAURE, 1987; FAURE; SUAUD, 1999; DEFRANCE, 1995; POCIELLO, 1998). Portanto, estou paradoxalmente na situação daquele que é levado a falar de Sociologia do Esporte para especialistas sem ser, eu mesmo, um deles. 
Mas o paradoxo é apenas aparente, pois em "Sociologia do Esporte" o mais importante, para mim, é "Sociologia" (que se diferencia de "Psicologia", "Didática" ou "Pedagogia", como bem o sabem aqueles que exercem a atividade de sociólogo em espaços acadêmicos pluridisciplinares) e não "Esporte". Não se deveria jamais fixar (ou deixar que fossem fixados pelas instituições) limites para seus campos de investigação, aceitando ser de uma vez por todas "sociólogo da família", "sociólogo da educação", "sociólogo do trabalho", "sociólogo da arte" ou "sociólogo do esporte"2. Ao ler trabalhos de pesquisas, é possível ver, aliás, o quanto seria desastroso falar sociologicamente de esporte sem falar de diversas maneiras das socializações familiar e escolar, dos processos de profissionalização ou de medicalização, das políticas públicas, da ciência e da técnica, etc. Todo cientista se define, principalmente e acima de tudo, por sua disciplina, isto é, por um ponto de vista de conhecimento específico, e não por seus objetos (ainda que não se deva, evidentemente, deduzir disso que o bom sociólogo poderia se contentar em examinar superficialmente seus objetos e áreas de estudo) (PANOSKY, 1967).

Entre os anos 1960 e 1970, a Sociologia da Educação era, para os sociólogos, a Sociologia "geral" por excelência. Ela voltou a ser uma Sociologia setorial (ou "especializada", como dizem os manuais e os programas de disciplina) desde que foi abandonada por pesquisadores que tinham como ambição trazer à tona aspectos fundamentais do mundo social através ou a partir da escola, e ocupada por especialistas da escola. Os sociólogos que trabalham com realidades esportivas deveriam ter como ambição serem sociólogos "generalistas", não no sentido de sociólogos que abandonam a área

\footnotetext{
2Por outro lado, não é certo que a sociologia possa tomar a liberdade de dividir as áreas como ela faz, em parcelas cada vez menores. Por querer muito se centrar e se concentrar em um universo ou em um subuniverso singular, o analista acaba por perder o foco, esquecendo-se de que uma parte da "verdade" (razão de ser, princípios estruturantes ou explicativos) das práticas se encontra frequentemente fora do universo ou do subuniverso em questão. Uma forte divisão do trabalho intelectual, que teria como consequência formar historiadores da arte (e, mais precisamente, de determinado tipo de arte) eruditos, mas limitados, tornaria impossível uma interpretação como a que foi proposta por Erwin Panofsky, 1967). Os danos científicos seriam evidentemente muito grandes.
} 
para dissertar de maneira geral sobre o "esporte em nossas sociedades", mas, sim, de protagonistas, teoricamente inventivos e metodologicamente inovadores. Essa é a única maneira de não ser cientificamente dominado ou, pensando-se em si mesmo como um sociólogo "especializado", de aceitar sê-lo.

Questionei-me, então, como poderia ser útil para os que conhecem muito melhor essa área do que eu. Para começar, dando exemplos do que a Sociologia do Esporte - como qualquer outra sociologia, aliás - não deve ser e apoiando com essa crítica aqueles que trabalham diariamente na construção de uma sociologia científica do esporte. Em seguida, propondo uma série de linhas de pesquisas articuladas e fazendo certas questões e algumas observações ou sugestões, do meu ponto de vista de sociólogo disposicionalista. Dizendo, por fim, por que penso que a Sociologia do Esporte poderia ser um lugar essencial de renovação e de progressão de uma Sociologia da educação que se reconciliaria com suas ambições científicas de Sociologia da socialização.

\section{SUPERINTERPRETAÇÕES E TRATAMENTOS INCORRETOS}

Como a maior parte dos objetos classificados precipitadamente como pertencentes à "cultura de massa", o esporte é objeto e vítima de múltiplas superinterpretações de discursos "nem mesmo falsos" (como diziam Pierre Bourdieu e Jean-Claude Passeron) que se apoiam em exemplos falsamente concretos a serviço de teses sobre as quais se pode dizer, sem grande injustiça, que são verdadeiramente abstratas e, às vezes, até mesmo realmente delirantes. Essas teses com frequência estabelecem analogias superficiais entre o esporte e determinado fenômeno ou entre o esporte e a "sociedade" em sua totalidade. Os ensaístas mais desleixados se servem assim do esporte para desenvolver as teses mais bizarras. $\mathrm{O}$ que se pode ler sobre $\mathrm{o}$ esporte em "grandes" editoras e nas coleções "de prestígio" é, desse ponto de vista, bastante próximo do que Jacques Bouveresse analisou em Prodígios e Vertigens da Analogia, citando Musil, comentador de 
Spengler, mais precisamente em sua obra O Declínio do Ocidente. A abordagem de Splenger, escrevia Musil, "evoca o zoólogo que classificaria os cachorros, as mesas, as cadeiras e as equações de $4^{\circ}$ grau entre os quadrúpedes". Na sequência, Musil dá uma demonstração muito irônica da maneira como se poderia, aplicandose esse tipo de procedimento, justificar a definição da borboleta como sendo o chinês anão alado da Europa Central:

Há borboletas amarelo-limão; há também chineses amarelo-limão. De certa maneira, é possível então definir a borboleta: chinês anão alado da Europa Central. Borboletas e chineses são considerados símbolos da volúpia. Vislumbra-se, pela primeira vez, a possibilidade de uma congruência, nunca antes estudada, entre o grande período da fauna lepidóptera e a civilização chinesa. $\mathrm{O}$ fato de a borboleta ter asas e o chinês não é apenas um fenômeno superficial. Mesmo que um zoólogo tivesse compreendido nem que fosse uma ínfima parte das últimas e das mais profundas descobertas da técnica, não caberia a mim ser o primeiro a examinar por que as borboletas não inventaram a pólvora: precisamente porque os chineses as precederam. A predileção suicida de algumas espécies noturnas pelas lâmpadas acesas é ainda uma sequela, dificilmente explicável para a compreensão diurna, dessa relação morfológica com a China (BOUVERESSE, 1999, p. 20-21).

Armado dessa crítica, o sociólogo pode apenas constatar a frequência desse tipo de brincadeira semântica em muitos textos sobre o esporte. Assim, um filósofo do mundo social, Gilles Lipovetsky, procede da mesma maneira em A Era do Vazio - Ensaios sobre o Individualismo Contemporaneo, quando escreve: "Windsurfe, skate, asa-delta, a sociedade pós-moderna é a era do deslizar, imagem esportiva que ilustra da maneira mais próxima possível uma época em que a res publica não tem mais elo sólido, não tem mais ancoragem emocional estável." (LIPOVETSKY, 1993, p. 20). 
O procedimento retórico é simples: busca-se um ponto comum aparente entre algumas práticas esportivas, nesse caso, o "deslizar" (e é por isso que o leitor fica surpreso ao não ver mencionada a patinação artística, o esqui, o trenó, a corrida de trenós... Possivelmente porque essas práticas "soam" menos pós-modernas) e, ao custo de algumas distorções semânticas, são citados fenômenos de gênero completamente distinto que parecem comportar um deslizamento ou que podem ser caracterizados por um deslizamento: deslizamento das instituições, instabilidades afetiva, conjugal ou profissional, etc. Pensa-se, então, estar diante de uma interpretação profunda, penetrante, enquanto o autor apenas jogou com as palavras, em última análise, deslizando de maneira pouco controlada de um sentido a outro (e participando, assim, do movimento de deslizamento universal característico da pós-modernidade...). Só a frase citada já bastaria para provocar, em qualquer leitor um pouco crítico e racional, uma série de questionamentos do tipo: por que esses esportes e não outros? O que se entende exatamente por res publica? Quais são os indicadores da ausência de "elo sólido" ou de "ancoragem emocional"? Onde o autor situa o momento em que essa res publica perdeu todo elo sólido e ancoragem emocional, já que escreve que ela não tem "mais" elo e ancoragem? É possível estabelecer uma ligação entre um fenômeno de ordem física e um fenômeno de ordem política? Mas antes mesmo que você tenha tido tempo de fazer essas questões que retardam consideravelmente a leitura, o autor o inunda com novas imagens, novas analogias ou novas interpretações tão obscuras (portanto, "profundas") que o inebriam (se você gostar de bebida) ou o fatigam quando você simplesmente procura (e sem dúvida meio "estupidamente") entender.

Devo esclarecer, para aqueles que se perguntarem por que "ataco" um filósofo, que Gilles Lipovetsky é eventualmente citado, por sociólogos de "renome", como um autor que tem o mérito de apontar um fenômeno social tão central quanto o "triunfo do individualismo" ou "o declínio do indivíduo da sociedade clássica". Por outro lado, muitos sociólogos franceses mostram, através de uma escrita tão clara e argumentada quanto a de Lipovetsky, que o 
ensaísmo desleixado não é um mal menor de nossa disciplina, mas sobretudo uma patologia ${ }^{3}$ recorrente contra a qual é preciso lutar incessantemente; lutar com uma chance muito pequena de conseguir mudar aqueles que se critica, mas com o objetivo essencial de não deixar os novatos na disciplina pensarem que é normal e admissível fazer e escrever sociologia dessa maneira.

Encontra-se o mesmo tipo de operação retórica em um autor autoproclamado "sociólogo de ação", Paul Yonnet, que em Jeux, modes et masses estabelece uma analogia das mais arriscadas entre cultura da resistência e crise energética mundial, para interpretar a escalada do jogging a partir dos anos 1970:

O surgimento súbito - no início dos anos 1970 - de uma cultura da resistência destinada a se difundir apenas nas sociedades ocidentais, sob formas principalmente - mas não exclusivamente esportivas inéditas, pode ser relacionado ao principal acontecimento dessa época, a vasta crise ao mesmo tempo econômica, energética e ideológica que agita o Ocidente. Essa crise se manifesta na virada dos anos 1970-71, à sombra de relatórios já extremamente negativos, dentre os quais o do Clube de Roma, sobre o futuro energético e demográfico do mundo. É por isso que essa crise pode ser chamada de crise do sistema econômico, mas também de crise de confiança e crise de consciência. [...]. O rareamento dos recursos, agravado pela "chantagem dos países produtores", exige a busca por uma nova economia das energias, a revisão das normas do sistema socioeconômico ocidental (crescimento menor, até mesmo crescimento zero) e o uso de energias de substituição (nuclear, biomassa, solar, eólica...). Ora, observemos bem as características próprias do esforço de resistência no praticante de jogging: ele se define como a busca de uma absorção/utilização máxima de oxigênio (fonte de energia vital), combinada com uma assimilação racional de alimentos essencialmente

\footnotetext{
${ }^{3}$ Era em termos de "doença de linguagem" ou de "patologia de linguagem" que Ludwig Wittgenstein concebia uma grande parte dos problemas da Filosofia.
} 
não proteicos (alimentos que não deveriam rarear, ao contrário das proteínas animais, pois sua produção exige um menor consumo energético). Em um contexto de rareamento dos recursos (se, amanhã, fosse preciso abandonar o automóvel, comer menos carne, etc.), o praticante de jogging busca, para seu corpo, uma nova economia energética [...], ele revisa seu padrão de vida (fumo, álcool, ritmo de vida, etc.), literalmente, ele se economiza, buscando produzir uma energia de substituição, a energia muscular. Em suma, o jogging se dispõe homologicamente em relação à crise do anos 1970. Não somente ele assinala a passagem de uma sociedade do sprint e do crescimento a uma sociedade da duração e do estado estacionário, mas também prepara o indivíduo para as piores eventualidades ecológicas. Esse é um aprendizado típico de uma conduta de sobrevivência, com sua sequência de imperativos (preparar-se para os sofrimentos físicos e psíquicos, mas permanecer em equilíbrio de oxigênio, maximizar em qualquer circunstância e em qualquer lugar a exploração útil de fontes de energias restritas), ele é a contraparte consensual da resposta social marginal trazida no "retorno à terra e à natureza" aos questionamentos sobre a perpetuação do homem originados pela crise energética. (YONNET, 1985, p. 121. Grifo do autor)

Notaremos, na ocasião, o total desvio da palavra "observação" nesse texto, assim como em tantos outros. De fato, não há nada aqui que se pareça com uma verdadeira observação científica organizada. Fala-se constantemente do "praticante de jogging" (em geral) e ele é correlacionado a fatos que não têm nenhum ponto em comum entre si além daqueles inventados por um intérprete superinterpretativo, provido de imaginação. Seria possível mostrar, em muitos casos, que, sob a aparência de profundidade inigualável, uma parcela das interpretações que circulam são, na realidade, produto de confusões e de ilusões de um tipo bastante elementar.

Eu poderia desenvolver o mesmo tipo de crítica a propósito de outros autores que conseguem fazer do esporte o símbolo por 
excelência da democracia ou o novo ópio do povo, portador de todos os males possíveis e imagináveis. O esporte, instrumento e símbolo da democracia ou meio de opressão e de condicionamento ideológico? Em todos os casos (analogias primitivas ou outros problemas), as teses defendidas pecam por sua precipitação teórica e pela ausência de trabalho empírico suficientemente preciso e rigoroso.

\section{UM PROGRAMA DE ESTUDO DISPOSICIONALISTA E CONTEXTUALISTA}

No conjunto das possíveis abordagens sociológicas do esporte e das atividades corporais, parece-me que a tradição da sociologia disposicionalista está entre as mais férteis. Trata-se fundamentalmente de uma sociologia da socialização que estuda os traços disposicionais deixados pelas experiências sociais e a maneira como essas disposições a sentir, acreditar e agir é desencadeada (ou desativada) em contextos variados de ação $0^{4}$.

$\mathrm{O}$ programa completo de uma sociologia disposicionalista e contextualista do esporte deveria comportar cinco grandes partes:

1) Primeiramente, um programa de estudos deveria logicamente partir da constatação da existência de não-praticantes ou de praticantes muito ocasionais, inclusive entre os mais jovens ${ }^{5}$ : quais são as disposições sociais dos que recusam ou rejeitam qualquer atividade esportiva ou corporal autônoma? Que relação socialmente determinada com seu próprio corpo deve-se manter para achar ridículo, insignificante ou insuportável esse tipo de atividades? Que

\footnotetext{
${ }^{4} \mathrm{~A}$ sociologia disposicionalista teve, por vezes, muita tendência a negligenciar os efeitos (facilitadores ou inibidores) dos contextos sobre as disposições incorporadas e, da mesma maneira, negligenciar o estudo dos contextos e de suas propriedades. Fiz uma crítica razoável dessa tendência em L'Homme pluriel, op. cit. Nesse sentido, é preciso, para ser mais justo, falar de sociologia indissociavelmente disposicionalista et contextualista.

${ }^{5}$ A pesquisa Emploi du temps 1998-1999 do INSEE ( $\mathrm{N}=16.200$ de 15 anos ou mais) mostrou que $53,8 \%$ das pessoas interrogadas não praticaram nenhuma atividade física ao longo das quatro últimas semanas $(27,1 \%$ praticaram uma; $18 \%$ praticaram duas ou mais). É preciso comparar esses $53,8 \%$ de não-praticantes com os $41,6 \%$ que não praticaram nenhuma atividade cultural e com os $47,4 \%$ que não praticaram nem bricolagem nem jardinagem durante o mesmo período. Os não-praticantes regulares de esporte são significativamente mais numerosos que os não-praticantes regulares dessas atividades culturais, também chamadas de semilazeres (DEGENNE, A. ; LEBEAUX, M.-O. ; MARRY, C., 2002, p. 95).
} 
experiências sociais contribuíram para formar as representações negativas dessas atividades? Em que medida, por exemplo, a educação física e esportiva, tal como ensinada na escola, contribui tanto para desestimular quanto para criar o gosto pelo esporte em uma parcela dos alunos?

2) Em seguida, dever-se-ia realizar um estudo sobre as disposições sociais constituídas em família que incitam à prática de um tipo de esporte mais do que outro, a fim de compreender as maiores afinidades sociais entre grupos sociais ou categorias sociais (e. g. sexuadas) e atividades corporais ou esportivas singulares para, ao mesmo tempo, obter meios para explicar a distribuição socialmente diferenciada dos diferentes esportes (equitação, remo, tênis, rúgbi, futebol, etc.).

Após ter destacado as grandes tendências estatísticas, é possível se perguntar também quais são as singularidades disposicionais daqueles que são estatisticamente atípicos, praticando um esporte que não é da sua "classe" ou "gênero" (como fez Christine Mennesson, ao trabalhar sobre as moças que praticam halterofilismo, boxe e futebol). (MENNESSON, 2000, p. 95).

Em todos os casos, cada atividade esportiva ou corporal, com suas propriedades técnicas, corporais, morais, organizacionais, midiáticas, etc., constitui convites ou barreiras à expressão das disposições socialmente constituídas pelas instâncias de socialização anteriores (BORDIEU, 1987, p. 209). E sua diversidade nas sociedades modernas altamente diferenciadas diz muito sobre a pluralidade das disposições e sobre a complexidade dos patrimônios de disposições individuais ou coletivas geradas por esse tipo de formações sociais (LAHIRE, 2004). Trabalhos seriam beneficiados, desse ponto de vista, ao tratarem do estado da divisão social do trabalho esportivo, especialmente da história (de média e longa duração) do processo de diferenciação das atividades físicas e esportivas.

3) Após a análise das grandes afinidades sociais, que explica a distribuição não-aleatória dos praticantes em função de suas propriedades sociais, é importante estudar as maneiras socialmente diferenciadas de praticar o "mesmo" esporte ou a "mesma" atividade 
corporal: sabendo-se que um esporte acolhe sempre públicos socialmente diversificados (mesmo que em proporções muito variadas, pelas razões que o ponto precedente lembrou), é possível tentar compreender como as diferentes categorias de praticantes se apropriam da atividade em questão, o que eles investem nela de diferente, as propriedades da atividade de que elas gostam mais ou menos, até mesmo detestam ${ }^{6}$; após o estudo das probabilidades diferenciais de acesso a um ou a outro esporte em função das propriedades sociais, e mais precisamente das disposições sociais dos praticantes, é o estudo das diferentes maneiras de se apropriar do mesmo esporte que é visado. Seria possível chamar isso de estudo dos estilos de práticas.

Esse tipo de estudo deve evitar que caiamos na armadilha de linguagem que consiste em nos levar a crer que o que denominamos do mesmo modo (e. g. o "futebol" em todo lugar, em um clube e fora dele, entre amigos nos fundos de um prédio ou em um pátio de escola, em um grande clube e em um clube pequeno, em um que faz treinamento sistemático e racional e em outro que privilegia o convívio entre seus membros, etc.) seria necessariamente próximo na realidade. Isso seria ir, como dizia Ludwig Wittgenstein, do substantivo à substância. $\mathrm{O}$ mesmo Wittgenstein aconselhava assim, em suas Investigações Filosóficas, a "desconfiar do poder que a linguagem tem de fazer com que tudo se pareça".

4) Entretanto, o programa não seria completo se fosse esquecido o estudo das disposições socialmente consolidadas, mas também especificamente constituídas no âmbito de determinado esporte ou de determinada atividade corporal; essas disposições são tanto disposições morais, políticas (no sentido de relação com a autoridade e com o poder, de disposições a viver de modo manifesto certas formas de exercício do poder), quanto disposições técnicas:

\footnotetext{
${ }^{6}$ Os comentários dos quadros estatísticos pressupõem com muita frequência que o praticante de uma atividade mantém necessariamente uma relação de adesão total à atividade, e que todas as propriedades da atividade estão em harmonia com as disposições incorporadas pelo praticante. Ora, qualquer descrição um pouco precisa das relações com as atividades (de trabalho, de lazer, de cultura...) reabre a discussão sobre essa pressuposição. Cf. LAHIRE, B. Portraits sociologiques, op. cit.
} 
ascetismo, entrega pessoal, individualismo ou hábitos de cooperação, espírito de grupo, espírito de competição, gosto pelo esforço, etc.

Na segunda parte de estudo que mencionei, a prática esportiva é vista essencialmente como o lugar de investimento, de atualização de disposições anteriormente constituídas. $\mathrm{O}$ esporte não é então considerado como um lugar de socialização, de construção de disposições específicas, mas como um espaço de atualização desses hábitos já incorporados. Ora, nem tudo reside nas condições sociais de possibilidade de acesso à atividade em questão; há também a lógica e as limitações próprias à atividade que deixam suas marcas nos praticantes. É preciso, então, completar imperativamente essa parte precedente caso não se deseje praticar um disposicionalismo sociológico estrito, que destacaria exclusivamente as socializações "primárias" e negligenciaria o estudo de todas as contribuições posteriores à fabricação social dos indivíduos. Tanto é assim que, para inverter a perspectiva mais corrente, é preciso, de fato, pensar que o esporte contribui ativamente para a construção das disposições sociais, ligadas especialmente ao grupo social de pertença e ao sexo. Ele tem uma parcela considerável na produção e na reprodução das diferenças sociais, especialmente das diferenças nos modos de ver, de sentir e de agir?

Seria preciso, contudo, evitar aqui qualquer exagero interpretativo ao se falar de habitus esportivo, qualquer que seja o tempo (longo ou curto) de prática esportiva acumulada. Parece-me que para não tornar amorfo esse conceito, no sentido de Max Weber (nos usos que fazem dele, em última análise, um vago equivalente de "cultura"), é preciso reservar o termo habitus esportivo a casos de praticantes muito empenhados na prática esportiva, até mesmo aos semiprofissionais da prática que dedicam todo seu tempo, pelo menos o essencial dele, ao treinamento e à prática do esporte, que orientam constantemente sua ação para essa atividade. Falar de habitus esportivo a propósito dos que praticam um esporte apenas

\footnotetext{
${ }^{7}$ Por exemplo, a dança ou a ginástica são matrizes tradicionais, mais ainda vivazes (respectivamente 5,2 milhões e 1,3 milhões de praticantes), constituídas por disposições femininas (79 $\%$ dos praticantes de dança e $80 \%$ dos ginastas são mulheres). Cf. Ministère des Sports et INSEP, 2002, p. 30.
} 
algumas horas por semana tange, ao que me parece, a um uso abusivo ou muito displicente de um conceito que destaca precisamente o caráter duradouro, permanente e transponível de um sistema coerente de disposições. Só se pode falar, portanto, de habitus (esportivo, religioso, escolar, etc.) quando a socialização é longa, sistemática e intensa. Nos outros casos, falar de disposições sociais específicas (e mais ou menos fortes), reforçadas pelas horas dedicadas ao esporte, parece muito mais adaptado e razoável (LAHIRE, 1999, 2002).

5) Enfim, para evocar questões que vão além da sociologia do esporte, parece-me que seria possível, também, buscar apreender utilmente em que medida há transferências possíveis de disposições adquiridas no esporte para outras áreas. Tentei mostrar, em meus trabalhos de pesquisas mais recentes, que as disposições eram sempre condicionadas e que seu grau de generalização ou o grau de extensão dos contextos de sua atualização era um problema que não podia ser resolvido a priori e de uma vez por todas, por simples decreto teórico. Somente pesquisas empíricas bem delimitadas e suficientemente precisas permitem avançar na compreensão dos fenômenos de transferências ou de inibição, de ativação ou de desativação das disposições socialmente constituídas. Uma disposição ascética constituída na e pela prática esportiva pode ser transferida para áreas escolares ou profissionais, ou o ascetismo corporal, físico não tem relação nenhuma com o ascetismo escolar ou com o ascetismo profissional? Em que medida disposições para a autodisciplina, o fair-play, a solidariedade, a competição, o respeito às regras ou à autoridade, que são (às vezes) construídas e empregadas ativamente em determinado contexto esportivo, podem ser transpostas ou transferidas para outras áreas de práticas, até mesmo generalizadas para todas as áreas, tornando-se disposições gerais e permanentes? A prática de um esporte pode ser um meio de forjar habilidades corporais ou disposições para agir e acreditar "rentáveis" ou "eficazes" em outras áreas de práticas?

Levanto essa série de questões porque me parece cientificamente muito imprudente pressupor a unidade e a coerência 
de um "sistema de disposições", estabelecendo-se, de imediato, que a prática esportiva atualiza uma relação com o corpo ou uma hexis corporal, que não passa de uma modalidade entre outras, de um habitus perfeitamente coerente em que todas as dimensões (corporais, vestimentárias, linguageiras, alimentares, culturais, políticas, etc.) se refletem e apenas expressam ou traduzem a mesma fórmula geradora das práticas. Quando Pierre Bourdieu escrevia que "[...] o elemento determinante do sistema das preferências é, aqui [em matéria de práticas esportivas], a relação com o corpo, com o envolvimento do corpo" e que "essa relação com o corpo é solidária de toda a relação com o mundo" (BORDIEU, 1987, p.204), ele postulava - no uso do singular como na ideia de solidariedade - a existência de um princípio unificador das condutas, de uma fórmula geradora dos comportamentos. Ora, essa ideia se deve mais, na minha opinião, ao mau hábito filosófico (especialmente fenomenológico) de falar "da relação com o mundo", do "ser no mundo", do que a um procedimento sociológico empiricamente fundamentado. $\mathrm{O}$ que dizer dos multipraticantes de esportes cujas propriedades intrínsecas nem sempre parecem compatíveis? O que dizer dos praticantes de esportes estatisticamente atípicos para sua categoria ou seu grupo? E dos indivíduos com propriedades sociais (no sentido amplo) muito próximas e que têm, contudo, comportamentos muito diferentes frente ao esporte (não-praticantes, monopraticantes ou multipraticantes)?

Para resumir os principais pontos desse programa de estudo, seria possível dizer que uma sociologia indissociavelmente disposicionalista e contextualista do esporte e das atividades corporais deve executar o estudo conjunto das disposições sociais que condicionam o acesso à prática ou o tornam impossível, das disposições esportivas requeridas e especificamente constituídas na própria prática, e dos diferentes estilos de jogo ou de prática observados no cruzamento das propriedades dos praticantes e das propriedades da atividade.

Contra as visões substancialistas das atividades sociais, é preciso lembrar que nenhum esporte encerra em si mesmo uma série de 
significações ou de propriedades culturais, mas que é suscetível de sofrer apropriações múltiplas, socialmente diferenciadas (conforme o sexo, a classe social, a idade, etc.). Porém, contra as visões muito românticas que colocam generosamente nas mãos e na cabeça de cada praticante uma capacidade infinita de invenções, de rodeios, de astúcia, de desvios ou de "bricolagens", é preciso ainda assim lembrar duas coisas:

- por um lado, que nenhuma apropriação ou desvio mudará nada de fato; por exemplo, que a luta é um esporte de combate, que supõe o combate direto de dois adversários, ou que o golfe supõe uma relação mais indireta com concorrentes com os quais a disputa se dá somente após a comparação de desempenhos individuais mais do que por enfrentamentos diretos (e que, se fosse introduzida experimentalmente uma bola na luta greco-romana ou confrontos diretos entre adversários que tentassem, por exemplo, ser os primeiros a golpear a bola de golfe, se alteraria radicalmente a própria natureza das atividades em questão);

- por outro lado, quanto mais os esportes são codificados (o que é o caso de todos os esportes de competição), mais o campo das apropriações possíveis se restringe, reduzindo-se a diferenças de estilos que podem ser imperceptíveis aos olhos não treinados dos leigos. Há uma resistência e uma autonomia próprias ao que podemos chamar de "propriedades formais da prática esportiva." (DARBON, 2002, p 1-27).

\section{Uma possível RENOVAÇÃo da Sociologia da EducaçÃo}

Gostaria de concluir com um ponto importante, que é também uma espécie de apelo. Penso que a sociologia disposicionalista do esporte poderia constituir uma das bases de uma renovação da Sociologia da educação na França e, ao mesmo tempo, de um desenvolvimento da Sociologia da Infância e da Adolescência em vias de constituição. Com efeito, a Sociologia da educação vem abandonando largamente, nos últimos vinte anos, a tarefa de análise sociogenética dos processos de construção dos indivíduos para se tornar uma sociologia especializada 
em políticas educativas (locais ou nacionais), em grandes dispositivos educativos, etc.

O esporte, com seus programas de treinamento mais ou menos sistemático e duradouro, seus períodos de prova, seus resultados e suas sanções positivas ou negativas é, primeiramente e acima de tudo, uma experiência socializadora que trabalha os indivíduos que investem nela, que modela seus corpos, mas também sua relação com o esforço e o sofrimento, sua moral, sua relação com o poder, sua relação com o coletivo, seu espírito de solidariedade na competição ou de competição na solidariedade, etc. As práticas esportivas constituem, portanto, um laboratório formidável em que os laços entre formas de relação de aprendizagem, tipos de disposição, saberes e savoir-faire e formas de exercício do poder ou da autoridade podem ser apreendidos. 
Dispositions and contexts of action: sport in issues

Abstract: In this essay, even putting himself in the condition of not exactly a sport sociologist, the author wonders how his text can be useful to those who know this area much better than him. Answering this question, he starts by giving examples of things Sport Sociology should not be; with this criticism he ends up by supporting those who work daily on the construction of a scientific sport sociology. Following, based on the point of view of a sociologist of dispositions, he proposes a series of articulated lines of research, from which a set of issues and some observations and/or suggestions. Finally, he says why he thinks that Sport Sociology could be a key place for renovation and progression of an educational Sociology that would reconciliate with its scientific ambitions of socialization Sociology.

Keywords: Soccer. Sociology, sports. Education.

\section{Disposiciones y contextos de acción: el deporte} en discusión.

Resumen: En este ensayo, mismo se colocando em la condición de no ser exactamente un sociólogo del deporte, el autor pregunta como su texto podría ser útil para aquellos que conocen esa área mejor que él. En respuesta a esa cuestión, inicia dando ejemplos de lo que la Sociología del Deporte no debe ser; con esa crítica, acaba apoyando aquellos que trabajan diariamente en la construcción de una sociologia científica del deporte. Seguidamente, con base en el punto de vista de sociólogo disposicionalista, propone una serie de líneas articuladas de investigación, a partir de un conjunto de cuestionamientos y/o sugerencias. Finalmente, explica porque piensa que la Sociología del Deporte podría ser un lugar esencial de renovación y de progresión de una Sociología de La educación que se reconciliaría con sus ambiciones científicas de Sociología de la socialización.

Palabras clave: Fútbol. Sociología del deporte. Educación. 


\section{REFERÊNCIAS}

BOURDIEU, P.. Programme pour une sociologie du sport: Choses dites. Paris : Minuit, 1987.

BOUVERESSE, J.. Prodiges et vertiges de l'analogie: de l'abus des belleslettres dans la pensée. Paris : Raisons d'agir, 1999.

CLÉMENT, J.-P.. Les apports de la sociologie de P. Bourdieu. Revue STAPS, Paris, n. 35 , p. 41-49, oct. 1994.

CLÉMENT, J.-P.. La force, la souplesse et l'harmonie. Étude comparée de trois sports de combat . In : POCIELLO, C. (dir.). Sports et Société. Paris: Vigot, 1998. p. 285-301.

DARBON, S.. Pour une anthropologie des pratiques sportives. Propriétés formelles et rapport au corps dans le rugby à XV. Techniques et Culture, Marseille, n.39, p. 1-27, 2002.

DEFRANCE, J.. Sociologie du sport. Paris: La Découverte, 1995.

DEGENNE, A.; LEBEAUX, M.-O. ;MARRY, C.. Les usages du temps : cumuls d'activités et rythmes de vie. Économie et statistique, Paris, n. 352-353, p. 81- 99,2002.

ELIAS, N.; DUNNING ,E.. Sport et civilisation. La violence maîtrisée. Paris: Fayard, 1994.

FAURE, J.-M.. Sport, cultures et classes sociales. Nantes: Thèse d'État, 1987. $2 \mathrm{v}$.

FAURE, J.-M., SUAUD C.. Le Football professionnel à la française. Paris: PUF, 1999.

LAHIRE, B.. L'Homme pluriel. Les ressorts de l'action. Paris: Nathan, Essais \& Recherches, 1998.

LAHIRE, B.. Esquisse du programme scientifique d'une sociologie psychologique. Cahiers internationaux de sociologie, Paris, v. 106, p. 29-55, 1999.

LAHIRE, B.. Portraits sociologiques: Dispositions et variations individuelles. Paris : Nathan, Essais \& Recherches, 2002.

LAHIRE, B.. La Culture des individus: Dissonances culturelles et distinction de soi. Paris: La Découverte, Laboratoire des sciences sociales, 2004. 
LIPOVETSKY, G. L'Ère du vide: Essai sur l'individualisme contemporain. Paris: Gallimard, 1993.

MENNESSON, C.. Des femmes au monde des hommes: La construction de l'identité des femmes investies dans un sport " masculin ": Analyse comparée du football, des boxes poings-pieds et de l'haltérophilie. Paris: Thèse de sciences sociales, Université Paris V, 2000. 3 v.

MINISTÈRE DES SPORTS ET INSEP. Les Pratiques sportives en France. Enquête 2000. Paris, 2002.

PANOFSKY, E.. Architecture gothique et pensée scolastique. Paris: Minuit, 1967.

POCIELLO, C.. La force, l'énergie, la grâce et les réflexes. Le jeu complexe des dispositions culturelles et sportives. Sports et Société. Paris: Vigot, 1998.

YONNET, P.. Jeux, modes et masses: 1945-1985. Paris: Gallimard, 1985.

Autorizado pelo autor para publicação na revista Movimento em 18 jan. 2011. 
